\title{
The Relationship Between Performance Competence and Cardiorespiratory Fitness in Contemporary Dance
}

\author{
Dr. Sarah C. Needham-Beck, PhD ${ }^{1 *}$, Professor Matthew A. Wyon, PhD ${ }^{2,4}$, \& Professor Emma \\ Redding, $\mathrm{PhD}^{3,4}$ \\ ${ }^{1}$ Occupational Performance Research Group, Institute of Sport, University of Chichester, UK \\ ${ }^{2}$ Research Centre for Sport, Exercise and Performance, Institute for Sport, University of \\ Wolverhampton, Walsall, UK \\ ${ }^{3}$ Dance Science, Trinity Laban Conservatoire of Music and Dance, London, UK \\ ${ }^{4}$ National Institute of Dance Medicine and Science, London, UK
}

* Correspondence: Sarah Needham-Beck, Occupational Performance Research Group, Institute of Sport, University of Chichester, College Lane, Chichester, West Sussex, PO19 6PE

s.needham-beck@chi.ac.uk

\begin{abstract}
While a foundation of basic cardiorespiratory fitness is beneficial for coping with the physiological demands placed on the body through dance training and performance, the extent to which cardiorespiratory fitness levels are related to performance ability is not all-together clear. This study aimed to directly compare aerobic capacity $\left(\mathrm{VO}_{\text {2peak }}\right)$ and anaerobic threshold (AT), to an aesthetic competence measure (ACM) in student contemporary dancers. Participants were 18 contemporary dance students and all undertook a one-off treadmill test to volitional exhaustion in the week leading up to a performance to determine $\mathrm{VO}_{2 \text { peak }}$ and AT. In the same week, a final rehearsal for the performance was filmed to allow retrospective analysis of specific performance competence. Mean $V O_{2 \text { peak }}$ values of $47.67 \pm 5.84 \mathrm{ml} . \mathrm{kg}^{-1} \cdot \mathrm{min}^{-1}$ and AT values of $43.18 \pm 7.72 \mathrm{ml} \cdot \mathrm{kg}^{-1} \cdot \mathrm{min}^{-1}(90.68 \pm 11.87$ $\% \mathrm{VO}_{2 \text { peak }}$ ) were recorded and mean total $\mathrm{ACM}$ score was $52.67 \pm 8.74$. No significant correlations were found between cardiorespiratory fitness variables and ACM scores. Regression analyses revealed experience level to be the only significant predictor of total $A C M$ score $\left(p<0.05, R^{2}=0.12, \operatorname{SEE}=11.91\right)$. The range of choreography used for assessment may limit the present study; nevertheless, as level of experience did significantly predict ACM total score, it is suggested that vocational dance training may be developing the performance and technical skills of students, but not sufficiently developing their physical conditioning. Further investigation of this topic is warranted to unpick the relevance of cardiorespiratory conditioning within dance training and performance, as either a supportive or crucial element.
\end{abstract}

Key words: performance competence, contemporary dance, cardiorespiratory fitness, anaerobic threshold 


\section{Introduction}

It is essential to highlight the importance of not just technique and other outwardly visible elements in dance performance, but also foundational physiological elements that underpin actions of the moving body. Koutedakis and Jamurtas, ${ }^{1}$ state that "dance performance... is a rather complex phenomenon made up of many elements that have direct and indirect effect on outcome" (p. 651652 ). Sport coaching has started to focus on the 'aggregation of marginal gains'. ${ }^{2}$ In this training philosophy, every factor that could marginally impact performance is acted upon and improved on the basis that the accumulation of all small gains will lead to a significant improvement overall. ${ }^{2}$ Sir Dave Brailsford, former Performance Director of British Cycling and General Manager of Team Sky, is often cited for adopting this training approach, throughout which it is emphasised that the basics have to be right first in order for these marginal gains to take effect, including elements such as nutrition, training, and sleep quality. ${ }^{2}$ Approaches such as this speak to the complex and multi-disciplinary nature of elite performance enhancement work and the importance of physical and psychological foundations upon which to build technique and skill based elements.

In dance of all genres, technical aspects are often the sole focus of training; however, the importance of cardiorespiratory fitness in dance training and performance has been a topic of investigation in previous research. ${ }^{1,3-14}$ Within this body of research, it is suggested that the importance of cardiorespiratory fitness for dancers goes beyond the potential benefit to aesthetic or performance ability of the dancer that is outwardly observable during performance and extends to general health benefits, fatigue resistance, and the dancers' overall ability to cope with the physiological demands placed upon them by training and performance. Previous research has; however, consistently reported low cardiorespiratory fitness levels in various dance populations, ${ }^{5,12}$ yet the extent to which this impacts upon the observable performance ability of the dancer is not clear.

A further difficulty of assessing performance ability in dancers is presented for research of this nature. Outcome measures within sports are often clearly defined and relate to maximum attainable speeds, distances, and heights as well as winning or losing. Defining clear outcome measures within noncompetitive dance forms is more challenging, although the necessity of these in order to be able to assess the efficacy of any training intervention is particularly noted within dance science research. Various qualitative measures for scoring or judging the performance ability or performance/ aesthetic competence of dancers have been developed for use in previous research., $815,16,3,11,4$ Measures commonly assess aspects such as posture/ alignment, skill/ technique, space, time/ rhythm, energy, phrasing, control, and performance quality/ presence, with descriptors given for each characteristic 
to aid scoring. Previous studies have attempted to document the direct relationship between fitness components and performance ability, as measured by such tools, and present conflicting results. Direct correlational analysis made between cardiorespiratory fitness levels (expressed as $\mathrm{VO}_{2 \max }$ or $\mathrm{HR}$ response to the dance aerobic fitness test) and measures of aesthetic competence have found no significant relationship between these variables. ${ }^{4,8}$ Indirect links have, however, been drawn between cardiorespiratory fitness and performance ability, through significant differences documented between fitness levels in dancers of different ranks in classical ballet (principals, soloists, first artists, and corps de ballet/ artists) ${ }^{17-19}$ and in student and professional contemporary dancers. ${ }^{20}$

Through the previous body of available literature, the extent to which a dancers' cardiorespiratory fitness level is directly related to the performance ability of that dancer is not all-together clear. It seems that professional dancers, and higher ranked professionals in ballet, have greater cardiorespiratory capacity than students, ${ }^{5,20}$ and lower ranked professionals in ballet, ${ }^{17-19}$ but correlational studies have found no significant relationship between aerobic fitness measures and measures of aesthetic competence. ${ }^{4,8} \mathrm{~A}$ number of benefits to higher cardiorespiratory fitness levels amongst dancers are seen to exist; however, we are currently only at the beginning of our understanding of how this translates in an individual dancer's outwardly visible skill and overall performance ability. Therefore, the aim of the present study was to directly compare aerobic capacity $\left(\mathrm{VO}_{2 \text { peak }}\right)$ and anaerobic threshold (AT), to a measure of aesthetic competence (ACM) in various levels of student contemporary dancers, to further examine the relationship.

\section{Methods}

A correlational, cross-sectional design was employed whereby two groups of student dancers undertook testing on a one-off basis.

\section{Participants}

Required sample size was calculated as 12 for magnitude of effect at $90 \%$ confidence intervals, based upon data provided by Angioi et al. ${ }^{3}$ Participants were 18 vocational contemporary dance students (14 female, 4 male) enrolled on either the first year of a Bachelor of Arts (BA) contemporary dance (UG; 7 female) or Masters of Arts (MA) dance performance (PG; 7 female, 4 male) degree programme. Basic anthropometric data collected including age (yrs), stature $(\mathrm{m})$, mass $(\mathrm{Kg})$, and calculation of body mass index (BMI; Kg. $\mathrm{m}^{-2}$ ) are displayed in Table 1. 
Table 1. Participant anthropometric data by gender and level of experience $(\mathrm{N}=18)$.

\begin{tabular}{cccccc} 
Gender & Experience & $\begin{array}{c}\text { Age } \\
(\mathbf{y r})\end{array}$ & $\begin{array}{c}\text { Height } \\
(\mathbf{m})\end{array}$ & $\begin{array}{c}\text { Mass } \\
(\mathrm{Kg})\end{array}$ & $\begin{array}{c}\text { BMI } \\
\left(\mathrm{Kg} . \mathbf{m}^{-2}\right)\end{array}$ \\
\hline $\begin{array}{c}\text { Female } \\
(\mathrm{N}=7)\end{array}$ & UG & $20 \pm 1.25$ & $1.63 \pm 0.11$ & $56.57 \pm 10.49$ & $21.26 \pm 3.52$ \\
\hline $\begin{array}{c}\text { Female } \\
(\mathrm{N}=7)\end{array}$ & PG & $24 \pm 3.00$ & $1.65 \pm 0.03$ & $57.21 \pm 4.54$ & $20.90 \pm 1.50$ \\
\hline $\begin{array}{c}\text { Male } \\
(\mathrm{N}=4)\end{array}$ & PG & $23 \pm 1.26$ & $1.76 \pm 0.05$ & $68.50 \pm 5.57$ & $22.13 \pm 1.79$ \\
\hline
\end{tabular}

Data are presented as mean \pm standard deviation. UG $=$ Undergraduate student dancers, $P G=$ Postgraduate student dancers.

The study received full ethical approval from the Institutional Research Ethics Committee prior to participant recruitment. All participants were over 18 years of age (range 18-30 years) and free from injury and illness at the time data collection. All participants were informed of possible risks and benefits of their participation prior to signing an approved informed consent document.

\section{Procedures}

Participants undertook a one-off treadmill test to volitional exhaustion to determine $\mathrm{VO}_{2 \text { peak }}$ and $\mathrm{AT}$ in the week leading up to a performance. In the same week, a final rehearsal for the performance was filmed to allow retrospective analysis of specific performance ability/ aesthetic competence. By using the final week before performance, the study aimed to capture the physiological condition of participants as close as possible to performance of the specific piece of repertoire examined.

Cardiorespiratory fitness testing

The adopted protocol followed specific recommendations made for testing dance populations, whereby the total time of the test is minimised. ${ }^{21}$ Initial start speed for the test was set based upon the corresponding speed at a heart rate of $120 \mathrm{~b} \cdot \mathrm{min}^{-1}$ for each individual participant during a fiveminute warm up (range 6-9 Km.h. ${ }^{-1}$ ). During the test, speed was increased by $1 \mathrm{Km} \cdot \mathrm{h}^{-1}$ every 1 minute at a constant incline of $1 \%$, until volitional cessation or until two of the following criteria were achieved: heart rate within $10 \mathrm{~b} \cdot \mathrm{min}^{-1}$ of age-predicted maximum, respiratory exchange ratio (RER) above $1.15, \mathrm{VO}_{2}$ plateau despite increase in speed, or inability to match treadmill speed. Throughout the test, participants wore a telemetric gas analyser (Metamax 3B, Cortex Biophysik GmbH, Germany) and a heart rate monitor (Polar, Polar Electro, Finland). On completion, participants cooled-down by walking at a speed of 5-6 Km.h ${ }^{-1}$ for a further 5 minutes or until a heart rate value of less than 100 b. $\min ^{-1}$ was achieved. 
Aesthetic competence testing

Due to its previous use in assessing the correlation between dance performance scores and aerobic fitness measures, the aesthetic competence measure (ACM) was used within the present study, as designed, validated, and used by Angioi et al. ${ }^{3}$ and used again later in a study comparing developments in physicality and aesthetic competence pre- and post- training intervention. ${ }^{4}$ During assessment using the ACM participants are given a rating from 1 to 10 for seven individual criteria: control of movements, spatial skills, accuracy of movements, technique, dynamics, timing, and rhythmical accuracy, performance qualities, and overall performance (for full description see Angioi et al. ${ }^{3}$ ). This measure demonstrated high inter-rater and intra-test-retest reliability in the initial reliability study. ${ }^{3}$

Video footage of each dancer was obtained from a final rehearsal in the week leading up to a performance. Full-cast rehearsals were filmed in order to retain spatial and timing characteristics of the piece and replicate performance as closely as possible. From rehearsal footage, a single film was produced, which included approximately 90 seconds of footage of each participant in turn, during which the individual participant was clearly visible. One external contemporary dance educator, with 18 years of experience, was recruited to undertake judging of the film. The judge was not familiar with any of the performance pieces or participants. Use of filmed footage allowed guidelines for scoring, as outlined by Angioi et al. ${ }^{3}$, to be followed, with the judge instructed to "1. to mark all dancers from the video on the same day, 2 . not to rewind the video clips at any time once the scoring procedure had begun, 3. to perform the assessment during the first hours of the morning on a pre-arranged specific day, and 4. to follow the scoring guidelines." (p.117).

\section{Data analysis}

All breath-by-breath data from the treadmill test was smoothed using a 6 breath moving average, followed by a reduction to 30 second average values, in accordance with suggested methods of previous literature. ${ }^{22,23}$ All data points were reported as relative $\mathrm{VO}_{2}\left(\mathrm{ml}_{\mathrm{kg}}{ }^{-1} \mathrm{~min}^{-1}\right)$ due to the weight bearing nature of the activity. $\mathrm{VO}_{2 \text { peak }}$ was reported, as the majority of participants did not fulfil criteria of a maximal effort, and was calculated as the highest 30 second average data point following smoothing procedures. Anaerobic threshold was determined using the V-slope method, ${ }^{24}$ taken as the point at which $\mathrm{VCO}_{2}$ output increased relative to $\mathrm{VO}_{2}$ intake and expressed as both $\mathrm{VO}_{2}\left(\mathrm{ml} \mathrm{kg}^{-1} \cdot \mathrm{min}^{-1}\right)$ and $\% \mathrm{VO}_{2 \text { peak. }}$. Scores provided for each of the seven categories of the ACM were used to calculate a total score for each dancer. 
The accepted $p$-value for significance was set at $p<0.05$ for all statistical analyses. All variables were checked for normal distribution using the Shapiro-Wilk statistic. All data were normally distributed. Pearson's $r$ correlation analyses were run to assess the relationship between each of the seven criteria separately on the ACM as well as total score, and measured $V_{2 \text { peak, }}$ AT $\left(\mathrm{ml} \cdot \mathrm{kg}^{-1} \cdot \mathrm{min}^{-1}\right)$, and AT\% $\left(\% \mathrm{VO}_{2 \text { peak }}\right)$. To ensure that all variance in scores (fitness and performance ability) were taken into account in the analysis, correlations were run for mean values as displayed in Tables 2 and 3 and not split by gender or experience level. Stepwise multiple regression analyses were also undertaken to establish which, if any, cardiorespiratory fitness variables or participant classifications were able to predict ACM total score. The independent variables were experience level, gender, $\mathrm{VO}_{2 \text { peak }}\left(\mathrm{ml}^{\mathrm{k}} \mathrm{kg}^{-}\right.$ $\left.{ }^{1} \cdot \mathrm{min}^{-1}\right)$, AT $\left(\mathrm{ml}^{\mathrm{kg}}{ }^{-1} \cdot \mathrm{min}^{-1}\right)$, and AT\% (\%VO 2 peak $)$, and the dependent variable was total ACM score. $\mathrm{R}^{2}$ values were reported as an estimate of effect size and standard error of the estimate (SEE) scores account for the amount of error in the prediction.

\section{Results}

Mean $\mathrm{VO}_{2 \text { peak }}$ values of $47.67 \pm 5.84 \mathrm{ml} \cdot \mathrm{kg}^{-1} \cdot \mathrm{min}^{-1}$ and AT values of $43.18 \pm 7.72 \mathrm{ml} \cdot \mathrm{kg}^{-1} \cdot \mathrm{min}^{-1}(90.68$ $\pm 11.87 \% \mathrm{VO}_{2 \text { peak }}$ ) were recorded. Males participants recorded higher aerobic fitness levels, and PG female $\mathrm{VO}_{2 \text { peak }}$ values were higher than those of UG females (Table 2).

Table 2. $\mathrm{VO}_{2 \text { peak }}$ and AT data of contemporary dance students by gender and level of experience.

\begin{tabular}{|c|c|c|c|c|}
\hline Gender & $\begin{array}{c}\text { Level of } \\
\text { Experience }\end{array}$ & 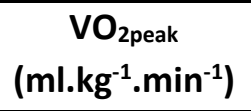 & 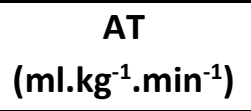 & $\begin{array}{c}\text { AT\% } \\
\left(\% \mathrm{VO}_{2 \text { peak }}\right)\end{array}$ \\
\hline $\begin{array}{l}\text { Female } \\
(N=7)\end{array}$ & UG & $44.92 \pm 4.06$ & $42.95 \pm 5.06$ & $95.48 \pm 4.96$ \\
\hline $\begin{array}{l}\text { Female } \\
(N=7)\end{array}$ & PG & $47.53 \pm 5.46$ & $39.33 \pm 7.67$ & $83.31 \pm 16.25$ \\
\hline $\begin{array}{l}\text { Male } \\
(N=4)\end{array}$ & PG & $52.73 \pm 7.01$ & $50.32 \pm 8.15$ & $95.18 \pm 3.75$ \\
\hline $\begin{array}{c}\text { Mean } \\
(N=18)\end{array}$ & Mean & $47.67 \pm 5.84$ & $43.18 \pm 7.72$ & $90.68 \pm 11.87$ \\
\hline
\end{tabular}

Data are presented as mean \pm standard deviation. $\mathrm{VO}_{2 \text { peak }}=$ Peak oxygen uptake, $\mathrm{AT}=$ Anaerobic threshold, UG = Undergraduate student dancers, $\mathrm{PG}=$ Postgraduate student dancers.

Mean total ACM score across all participants was $52.67 \pm 8.74$ out of a possible 70 points. Little variation is noted between mean scores of the different ACM criteria within groups, however PG scores are higher than UG scores throughout (Table 3). PG males display the highest total ACM score and UG females the lowest (Table 3). 
Results demonstrated no significant correlations between mean cardiorespiratory fitness variables and ACM scores (Figure 1). In line with trends displayed in Table 3, multiple regression analysis revealed experience level to be the only significant predictor of performance (total $A C M$ score) ( $p<0.05, R^{2}=0.12$, SEE=11.91).

Table 3. ACM scoring data of contemporary dance students by gender and level of experience.

\begin{tabular}{|c|c|c|c|c|c|c|c|c|c|}
\hline \multirow[b]{2}{*}{ Gender } & \multirow[b]{2}{*}{$\begin{array}{c}\text { Level of } \\
\text { Experience }\end{array}$} & \multicolumn{8}{|c|}{ ACM scoring criteria } \\
\hline & & 1 & 2 & 3 & 4 & 5 & 6 & 7 & Total score \\
\hline $\begin{array}{l}\text { Female } \\
(\mathrm{N}=7)\end{array}$ & UG & $6.71 \pm 1.11$ & $7.71 \pm 1.11$ & $7.71 \pm 1.50$ & $6.71 \pm 1.11$ & $7.00 \pm 0.82$ & $6.43 \pm 1.40$ & $6.71 \pm 1.89$ & $49.00 \pm 8.19$ \\
\hline $\begin{array}{l}\text { Female } \\
(N=7)\end{array}$ & PG & $7.71 \pm 1.38$ & $7.57 \pm 1.27$ & $7.86 \pm 1.35$ & $7.71 \pm 1.11$ & $8.29 \pm 0.95$ & $7.43 \pm 1.13$ & $7.57 \pm 1.40$ & $54.14 \pm 7.90$ \\
\hline $\begin{array}{l}\text { Male } \\
(N=4)\end{array}$ & PG & $7.50 \pm 1.73$ & $8.00 \pm 1.41$ & $8.25 \pm 1.71$ & $7.75 \pm 1.89$ & $8.50 \pm 1.29$ & $8.00 \pm 1.41$ & $8.50 \pm 1.91$ & $56.50 \pm 10.85$ \\
\hline $\begin{array}{c}\text { Mean } \\
(N=18)\end{array}$ & Mean & $7.28 \pm 1.36$ & $7.72 \pm 1.18$ & $7.89 \pm 1.41$ & $7.33 \pm 1.33$ & $7.83 \pm 1.15$ & $7.17 \pm 1.38$ & $7.44 \pm 1.76$ & $52.67 \pm 8.74$ \\
\hline
\end{tabular}

Data are presented as mean \pm standard deviation. $A C M=$ Aesthetic competence measure, $U G=$ Undergraduate student dancers, $P G=$ Postgraduate student dancers. $A C M$ criteria: 1 = control of movement, $2=$ spatial skills, $3=$ accuracy of movement, $4=$ technique, $5=$ dynamics, timing, and rhythmical accuracy, $6=$ performance qualities, $7=$ overall performance. 

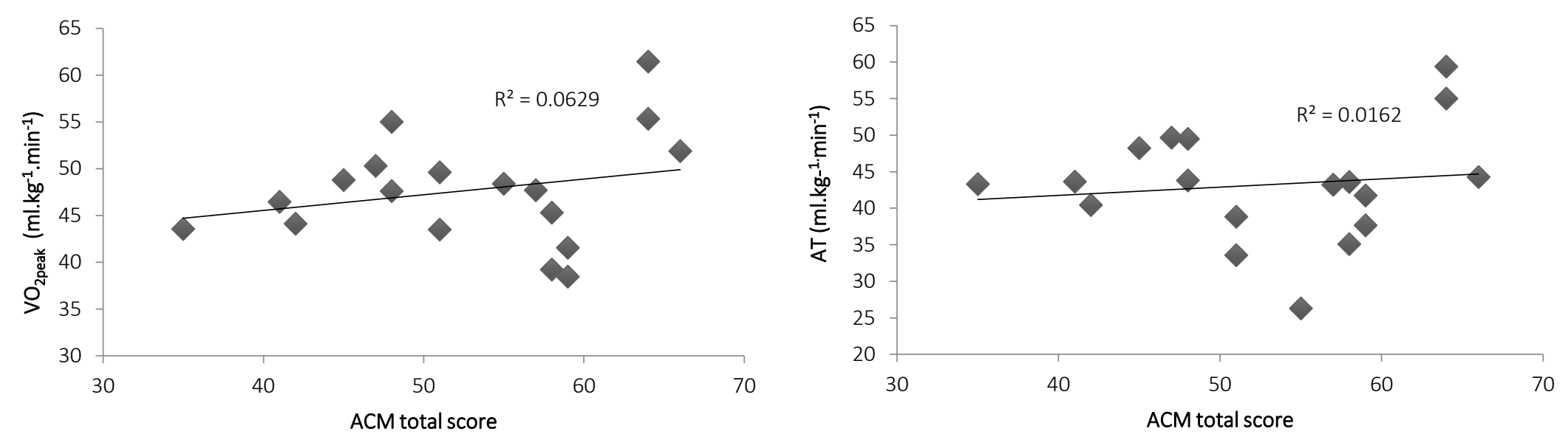

C

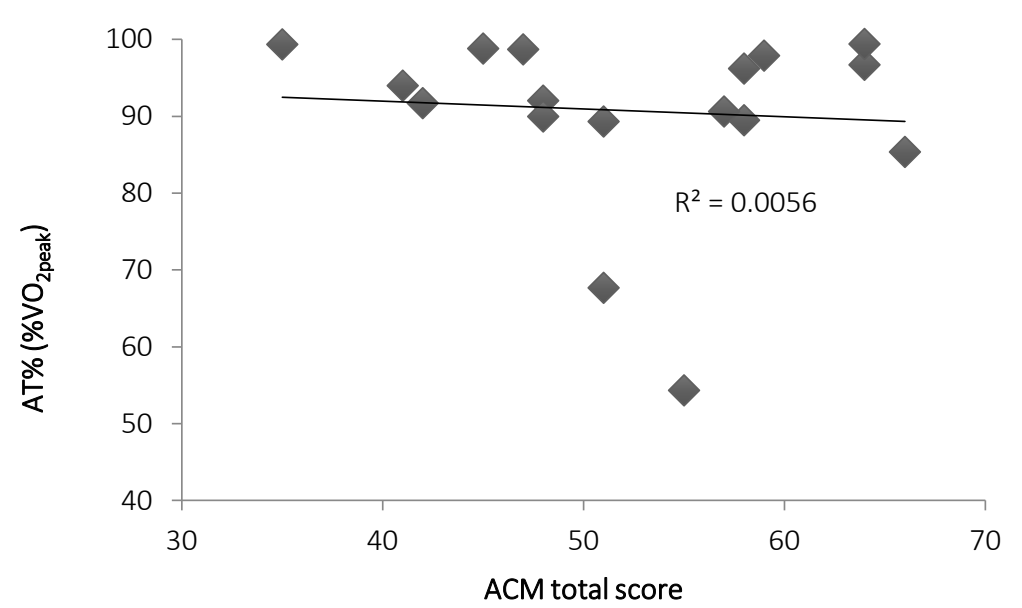

Figure 1. Correlation plot displaying the relationship between mean ACM total score and A) mean $\mathrm{VO}_{2 \text { peak, }} \mathrm{B}$ ) mean AT, and C) mean AT\% for all participants. $\mathrm{VO}_{2 \text { peak }}=$ Peak oxygen uptake, $\mathrm{AT}=$ Anaerobic threshold $\mathrm{ACM}=$ Aesthetic competence measure. 


\section{Discussion}

The aim of this study was to directly compare commonly used markers of cardiorespiratory fitness to a previously developed and used measure of aesthetic competence (ACM) in student contemporary dancers. Results of this study concur with those of Angioi et al. $^{3}$ that a direct correlation is not observable between measures of cardiorespiratory fitness and performance ability as measured by the ACM, despite differences in the measures of cardiorespiratory fitness used across the two studies. In the present study, both group and overall mean $\mathrm{VO}_{2 \text { peak }}$ values are higher than those previously reported for contemporary dance students, as reviewed by Angioi et al. ${ }^{5}$ (Table 2). Such comparison is not directly available for AT values, although values from various other dance genres for adult professionals and students range from $73.9-85.1 \% \mathrm{VO}_{2 \text { peak, }}{ }^{19,25,26}$ which is lower than the overall mean in the present study (Table 2). Higher scores were also found in individual criteria and total scores in the ACM than previous studies using the same measure ${ }^{3,4}$ (Table 3). Therefore, it appears that, on average, the dancers in the present study had higher cardiorespiratory fitness and performance levels than those of previous studies. However, the limited range of scores presented on both measures may have influenced the findings of the present study. In order to examine the relationship between variables accurately, the full spectrum of high and low scores for both variables is necessary to allow a direct comparison of high and low fit individuals with high and low scores on the ACM.

Level of experience was the only significant predictor of ACM total score. As dance is a high skill based activity this is perhaps unsurprising; however, it is also worth highlighting that the number of years of experience and training an individual dancer has completed are not necessarily directly related to their level of skill. Nevertheless, it is interesting to see that within two groups who are training at the same institution, and therefore under similar ethos and focus, the dancers who are further through their training score higher on the ACM. This may, however, also merely be reflective of the higher standard of the PG group, whereby only twelve dancers are chosen for the programme each year out of those who audition. The same high selection standards are not imposed on the UG group, which has an average year group size of 90 students. This higher skill level in the PG dancers may also be reflective of the importance of technical skill for successfully transitioning from student to professional dance, whereby only those with a high technical mastery of skills are likely to succeed. In support of this, Angioi et al. ${ }^{3}$ state that technical mastery of skills seems to be the essential factor in achieving aesthetic competence during dance performance.

Findings of this study further highlight the potential value of cardiorespiratory fitness as falling outside of the aesthetics of dance performance, emphasising the importance of a good foundation fitness 
level to support training and performance. A higher level of fitness theoretically should allow dancers to push their technical development further, by being able to train at a higher intensity for longer, or at a lower relative intensity for a given movement thereby preserving energy; however, the magnitude of this indirect impact upon aesthetic competence is perhaps difficult to quantify. As previously discussed, technical skill development is currently the focus of vocational dance training and while this is undoubtedly a very important aspect of dance performance, it is often developed at the detriment of other aspects which perhaps contribute more indirectly to performance. Injury rates continue to be high in dancers of all levels and fitness levels are consistently documented as low, suggesting that current training is not adequately addressing the supportive physiological development of dancers. Wyon and Redding ${ }^{27}$ state that enhancement of the aerobic system is required, particularly at the prerehearsal stage, in order to allow dancers to develop the physiological capability to cope with the stresses of performance.

There are some limitations of this study, which must be taken into account in analysing the results. Firstly, although possessing adequate power, the sample used exhibited limited variation about mean values for fitness and performance variables, the potential implications of which were previously discussed. A further limitation exists in the nature of the performance video clips used for ACM scoring, which was inconsistent both between and within groups. Most notably, dancers were assessed on different pieces of choreography. Confounding variables of temporal and intensity characteristics of the pieces, may alter perceptions of their ability to execute the movement fully. Furthermore, clips of each individual dancer were not taken from consistent time points within the piece; some were closer to the end of the piece, some closer to the beginning. As is the case with most dance performance some individual dancers also had bigger roles in the pieces than others and, therefore, spent a greater proportion of the time dancing. Therefore, levels of fatigue may have varied for different participants. Features of the piece such as these may help in determining the applicability of technique based measures as we may see decrements in technique in less fit dancers over a longer period of continuous dancing. This calls into question the applicability, validity, and reliability of performance and aesthetic competence measures to compare to fitness variables. The highly subjective nature of dance performance assessment means that it is challenging to assess the accuracy of any such tool developed for its measurement. Only one judge was used for scoring in the present study; however, using two or three judges in future research could help to identify inconsistencies in scoring, and allow further reliability analysis to be undertaken on the ACM. 


\section{Conclusions}

The primary finding of the present study was no significant relationship between cardiorespiratory fitness measures reported and aesthetic competence. Given the limitations of this study, a larger scale study is warranted with a more diverse sample and which takes into account many of the confounding variables mentioned above in its design. Further discussion and investigation of appropriate outcome measures for dance is also needed in order to allow more accurate appraisal of the impact of the various factors integral in building towards optimal performance from a multi-disciplinary viewpoint. The primary focus of current dance training practices remains on technical skill development; however, it appears that there is a strong enough evidence-based rationale for training to allow some portion of this focus to shift to ensuring appropriate physiological development. Further intervention studies are warranted to examine the potentially wide-ranging impacts of this approach.

\section{References}

1. Koutedakis $Y$, Jamurtas A. The Dancer as a Performing Athlete: Physiological Considerations. Sports Med. 2004;34(10):651-661.

2. Kirkland A, Hopker J, Jobson S. Learning from the success of British Cycing - perspectives on developing excellence in practice. Sport Exerc Sci. 2013;(35):22-23.

3. Angioi M, Metsios GS, Twitchett E, Koutedakis $\mathrm{Y}$, Wyon M. Association Between Selected Physical Fitness Parameters and Aesthetic Competence in Contemporary Dancers. J Dance Med Sci. 2009;13(4):115-123.

4. Angioi $M$, Metsios $G$, Twitchett EA, Koutedakis $Y$, Wyon $M$. Effects of supplemental training on fitness and aesthetic competence parameters in contemporary dance: a randomised controlled trial. Med Probl Perform Art. 2012;27(1):3-8. PMID: 22543316

5. Angioi M, Metsios G, Koutedakis $\mathrm{Y}$, Wyon M. Fitness in Contemporary Dance: A Systematic Review. Int J Sports Med. 2009;30(07):475-484.

6. Cohen A. Dance--Aerobic and Anaerobic. J Phys Educ Recreat Dance. 1984;55(3):51-53.

7. Kirkendall DT, Calabrese LH. Physiological aspects of dance. Clin Sports Med. 1983;2(3):525537. PMID: 6652701

8. Koutedakis Y, Hukam H, Metsios G, Nevill A, Giakas G, Jamurtas A, Myszkewycz L. The effects of three months of aerobic and strength training on selected performance- and fitness-related parameters in modern dance students. J Strength Cond Res. 2007;21(3):808-812. PMID: 17685714

9. Rafferty S. Considerations for Integrating Fitness into Dance Training. J Dance Med Sci. 2010;14(2):45-49.

10. Ramel E, Thorsson O, Wollmer P. Fitness training and its effect on musculoskeletal pain in professional ballet dancers. Scand J Med Sci Sports. 1997;7(5):293-298. 
11. Twitchett $E A$, Angioi $M$, Koutedakis $Y$, Wyon $M$. Do increases in selected fitness parameters affect the aesthetic aspects of classical ballet performance? Med Probl Perform Art.

2011;26(1):35-38. PMID: 21442135

12. Twitchett EA, Koutedakis Y, Wyon MA. Physiological Fitness Professional Classical Ballet Performance: A Brief Review. J Strength Cond Res. 2009;23(9):2732-2740.

13. Twitchett $E$, Brodrick A, Nevill AM, Koutedakis $Y$, Angioi M, Wyon M. Does physical fitness affect injury occurrence and time loss due to injury in elite vocational ballet students? J Dance Med Sci. 2010;14(1):26-31. PMID: 20214852

14. Wyon M. Cardiorespiratory Training for Dancers. J Dance Med Sci. 2005;9(1):7-12.

15. Chatfield SJ. A test for evaluating proficiency in dance. J Dance Med Sci. 2009;13(4):108-114. PMID: 19930812

16. Krasnow D, Chatfield SJ. Development of the "performance competence evaluation measure": assessing qualitative aspects of dance performance. J Dance Med Sci. 2009;13(4):101-107. PMID: 19930811

17. Schantz PG, Astrand PO. Physiological characteristics of classical ballet. Med Sci Sports Exerc. 1984;16(5):472-476. PMID: 6513765

18. Wyon MA, Deighan MA, Nevill AM, Doherty M, Morrison SL, Allen N, Jobson SJ, George S. The Cardiorespiratory Anthropometric, and Performance Characteristics of an International/National Touring Ballet Company. J Strength Cond Res. 2007;21(2):389-393.

19. Wyon MA, Allen N, Cloak R, Beck S, Davies P, Clarke F. Assessment of Maximum Aerobic Capacity and Anaerobic Threshold of Elite Ballet Dancers. Med Probl Perform Art. 2016;31(3):145-150. PMID: 27575290

20. Bronner S, Codman E, Hash-Campbell D, Ojofeitimi S. Differences in Preseason Aerobic Fitness Screening in Professional and Pre-professional Modern Dancers. J Dance Med Sci. 2016;20(1):11-22.

21. Wyon M. Testing an aesthetic athlete: contemporary dance and classical ballet dancers. In: Winter EM, Jones AM, Davison RCR, Bromley PD, Mercer T, editors. Sport Exerc Physiol Test Guidel Vol II - Exerc Clin Test Br Assoc Sport Exerc Sci Guide. London: Routledge; 2006.

22. James DVB, Sandals LE, Wood DM, Jones AM. Pulmonary gas exchange. In: Winter EM, Jones AM, Davison RCR, Bromley PD, Mercer T, editors. Sport Exerc Physiol Test Guidel Vol II - Exerc Clin Test Br Assoc Sport Exerc Sci Guide. London: Routledge; 2006.

23. Guidetti L, Emerenziani GP, Gallotta MC, Da Silva SG, Baldari C. Energy cost and energy sources of a ballet dance exercise in female adolescents with different technical ability. Eur J Appl Physiol. 2008;103(3):315-321. PMID: 18340457

24. Wasserman K, Hansen J, Sietsema K, Sue DY, Stringer WW, Sun X-G, Whipp BJ. Principles of Exercise Testing and Interpretation: Including Pathophysiology and Clinical Applications. 5th Revised edition. Lippincott Williams and Wilkins; 2011.

25. Maciejczyk M, Feć A. Evaluation of Aerobic Capacity and Energy Expenditure in Folk Dancers. Hum Mov. 2013;14(1):76-81. 
26. Oliveira SML, Simões HG, Moreira SR, Lima RM, Almeida JA, Ribeiro FMR, Puga GM, Campbell CSG. Physiological responses to a tap dance choreography: comparisons with graded exercise test and prescription recommendations. J Strength Cond Res. 2010;24(7):1954-1959. PMID: 20555280

27. Wyon MA, Redding E. Physiological monitoring of cardiorespiratory adaptations during rehearsal and performance of contemporary dance. J Strength Cond Res. 2005;19(3):611-614. PMID: 16095410 